\title{
FABULEUX HASARDS
}

\author{
Histoire de la découverte \\ de médicaments
}


This page intentionally left blank 


\title{
FABULEUX HASARDS
}

\author{
Histoire de la découverte \\ de médicaments
}

\section{Claude MONNERET et Claude BOHUON}

Préface de Maurice Tubiana

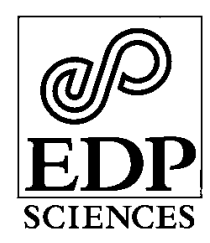

17, avenue du Hoggar - P.A. de Courtabœuf BP 112, 91944 Les Ulis Cedex A 
Adaptation de Michel Zelvelder.

Maquette et mise en pages : Facompo

Imprimé en France

ISBN : 978-2-7598-0378-1

Tous droits de traduction, d'adaptation et de reproduction par tous procédés, réservés pour tous pays. La loi du 11 mars 1957 n'autorisant, aux termes des alinéas 2 et 3 de l'article 41, d'une part, que les « copies ou reproductions strictement réservées à l'usage privé du copiste et non destinés à une utilisation collective », et d'autre part, que les analyses et les courtes citations dans un but d'exemple et d'illustration, «toute représentation intégrale, ou partielle, faite sans le consentement de l'auteur ou de ses ayants droit ou ayants cause est illicite » (alinéa $1^{\text {er }}$ de l'article 40). Cette représentation ou reproduction, par quelque procédé que ce soit, constituerait donc une contrefaçon sanctionnée par les articles 425 et suivants du code pénal.

(C) EDP Sciences, 2009 
Le hasard ne favorise que des esprits préparés.

L. Pasteur 
This page intentionally left blank 